\title{
La crisis del capitalismo y la periferia
}

Independientemente de mi persona considero que la iniciativa de estas conferencias es sumamente conveniente y oportuna en estos momentos, porque hay que esclarecer nuestro camino, que no está definitivamente esclarecido, sobre todo si se tiene en cuenta los nuevos acontecimientos que se producen en el campo de la política económica internacional y en el campo del desarrollo de nuestros países. La iniciativa es conveniente y oportuna, porque estamos presenciando no solamente la crisis del capitalismo sino la crisis de las ideologías, la crisis seria de las teorías convencionales que no nos permiten interpretar correctamente la realidad de los acontecimientos presentes sin ver con claridad el camino que se ha de seguir.

Las teorías convencionales tienen una gran falla a mi juicio, que es haber prescindido y seguir prescindiendo en forma sistemática de la estructura social y sus continuas mutaciones. En consecuencia, es imposible a la luz de esas teorías interpretar los fenómenos tan importantes que están ocurriendo. A mi juicio, esta crisis del capitalismo es una crisis estructural: una seria crisis estructural más compleja y difícil que la que mie tocó vivir a mí como joven economista en el decenio de 1930. Esa crisis fue una crisis cíclica, difícil, que se logró superar. Por el contrario, la crisis actual es una crisis que procede de la lógica interna del sistema, dada la estructura en que ese sistema se está movienclo. La manifestación más preocupante de esta crisis es el desequilibrio de carácter estructural entre el ritmo de consumo y el ritmo de la acumulación de capital reproductivo. Subrayo el término reproductivo porque se trata de aquel tipo de capital que aumenta el empleo y la productividad, y porque hay muchas otras formas viciosas de acumulación.

Voy a tratar de explicar en muy pocas palabras por qué sostengo que se trata de una crisis estructural. A mi juicio, la razón de ello es que la distribución del ingreso y la acumulación de capital son en gran parte las consecuencias del juego cambiante de relaciones sociales de poder que se derivan de las continuas mutaciones de la estructura de la sociedad que ocurren con la evolución de la técnica. Los estratos superiores de la sociedad tienen la manifiesta 
aptitud de apropiarse, debido a su situación estructural, de los frutos de una incesante productividad derivada del progreso técnico. Esta apropiación les permite, por un lado, acumular capital y, por otro, desenvolver, a veces frenéticamente, la sociedad privilegiada de consumo en desmedro del ritmo de acumulación de capital. Sorprenderá a muchos de ustedes que yo haga esta afirmación refiriéndome al centro dinámico principal del capitalísmo: los Estados Unidos de América. La razón de èllo es que creía que los problemas de acumulación habían sido resueltos allí, pero no han sido resueltos. Al contrario, y voy a tratar de decir por qué.

Hemos visto que por un lado están los estratos superiores con su poder de retención del fruto del progreso técnico; por otro está un fenómeno que se ha desarrollado y desenvuelto con progresiva intensidad, sobre todo después de la Segunda Guerra Mundial. Se trata del poder sindical y político de la fuerza de trabajo, poderes que le permiten disputar cada vez más el fruto del progreso técnico a los que se apropian de él en forma de excedente económico y que le permiten también disfrutar cada vez más de su participación e ir adquiriendo las formas de consumo de los estratos superiores. Hemos dicho poder sindical y poder político. El poder político lleva a la fuerza de trabajo a usar el mecanismo del Estado y a gravitar progresivamente en él para conseguir crecientes ventajas sociales. Por último, están el poder burocrático y militar que, como es notorio, también se han desenvuelto en forma hipertrófica. Esto ha dado lugar a que al consumo privilegiado de los estratos superiores se vaya agregando el consumo privado y social de la fuerza de trabajo en sus distintas categorías, y el consumo civil y el consumo militar del Estado.

Lo interesante es percibir el hecho fundamental de que al crecer estas distintas formas de consumo con la evolución de la estructura social, su crecimiento no se hace a expensas del consumo de los estratos superiores sino que se superpone al consumo de los estratos superiores hasta que, con el andar del tiempo, en la evolución del sistema, por la misma lógica interna del sistema, se llega a un momento en que el ritmo de crecimiento de las distintas clases de consumo que se superponen, tiende a sobrepasar el ritmo de la acumulación de capital, sobre todo del capital reproductivo, que como dije antes es el que engendra el crecimiento del empleo y la productividad y que, por lo tanto, tiene vital importancia en cualquier sistema. Cualquier sistema económico y social necesita un aumento constante y continuo de la acumulación de capital. Y he ahí lo que está pasando, a mi juicio, en los grandes países capitalistas, sobre todo en los Estados Unidos de América. El fenómeno que tanto preocupa en ese país es la disminución del ritmo de productividad. Ello puede deberse a una serie de factores, pero en mi opinión el factor más importante es ese desequilibrio de tipo estructural. No hay ninguna fuerza reguladora dentro del sistema 
que asegure una relación adecuada entre consumo y acumulación. Las leyes del mercado no tienen ninguna aptitud para regular el consumo y la acumulación. Tienen una gran virtud en otros aspectos. No estoy en desacuerdo con los que creen que las leyes del mercado tienen mucha importancia. La tienen, pero en un ámbito circunscrito. No pueden resolver los problemas fundamentales de la economía en una evolución estructural que ha llegado a la situación que acabo de mencionar.

Pero no solamente se resiente el ritmo de acumulación de capital sino que hay formas de capital que no aumentan la productividad, comenzando por el capital que se invierte para el consumo militar. Ese capital podrá tener otra eficacia, pero no tiene incidencia positiva sobre la productividad. Más aún, esta proliferación incesante de bienes y servicios que la evolución de la técnica estaba trayendo consigo - esta diversificación, también significa la acumulación de formas de capital que pueden obedecer al propósito de halagar al consumidor, excitar su sentido de jerarquáa social, y las otras finalidades, pero que no aumentan la productividad. Esa es otra manifestación de la crisis que es evidente en todas las sociedades y aún en las que son menos desarrolladas, como son las de nuestros países. Ello contribuye a acentuar el desequilibrio dinámico entre ritmo de consumo y ritmo de acumulación.

Finalmente, es un hecho notorio que una parte del gran incremento de productividad que hubo en la postguerra y que ha estimulado todas estas distintas formas de consumo estaba en parte basado sobre una falsedad. Era un aumento de productividad que se lograba a raíz de la explotación irresponsable de recursos naturales no renovables: el caso del petróleo es un ejemplo evidente. Para corregir este fenómeno tan importante para la humanidad es necesaria una mayor inversión de capital por unidad de producto. También hay que tener en cuenta el capital que será necesario para contrarrestar el fenómeno de deterioro del medio ambiente resultante de la ambivalencia de la técnica productiva. En consecuencia, hay una serie de fenómenos que resultan de la propia lógica interna del sistema y que están llevando a la crisis.

Entiéndaseme bien: cuando yo hablo de la crisis del capitalismo de los centros no estoy diciendo en forma alguna que es un fenómeno de decadencia del capitalismo. No lo es. Si en alguna época histórica el capitalismo ha demostrado un enorme impulso constructivo, basado por cierto en la ambivalencia de la técnica, ha sido $\sin$ duda en los años, los largos años que suceden a la Segunda Guerra Mundial, que parten de la postguerra y van hasta la primera mitad del decenio de 1970. Lo que ha ocurrido, a mi juicio, es que ese capitalismo, por su propia dinámica, ha desbordado sus cauces, se ha salido de madre y no hay en el sistema, en el funcionamiento espontáneo del sistema, nada que pueda encauzar ese fenómeno. No hay nada que pueda volver a dar nuevos cauces a ese 
fenómeno dinámico. No es que el problema no sea corregible, sino que su corrección no vendrá del juego de las leyes del mercado, de lo que se ha dado en llamar, en forma muy peregrina en los últimos años, la magia del mercado, sino de una acción consciente y deliberada del Estado sobre bases democráticas para crear un nuevo régimen macroeconómico de acumulación de capital y distribu. ción del ingreso, que impida esos desbordes que estamos presenciando con muy graves consecuencias.

Todavía no queremos convencernos de que esas consecuencias son sumamente graves y seguimos creyendo que hay soluciones fáciles, que es cuestión de aceptar algún compromiso, de que el sistema haga un sacrificio, para que éste vuelva a funcionar. Me refiero a las políticas monetaristas. ¿Cómo estas políticas monetaristas pretenden resolver este desequilibrio? ¿Cómo pretenden adecuar el ritmo de consumo a las necesidades de acumulación del sistema para corregir todos los males que he estado mencionando? Hay dos formas de monetarismo. Una forma de política monetarista es la de pretender corregir el desequilibrio de consumo restringiendo el consumo. $\mathrm{Y}$, ¿cómo se restringe el consumo? Se restringe mediante una política restrictiva del crédito, que contrae la actividad económica y que engendra desocupación. Es muy crudo el procedimiento, pero es lo que está detrás de un tipo de política monetarista. Se trata de crear desocupación hasta que la fuerza de trabajo se sienta dominada en su poder sindical y acepte la disminución de las remuneraciones en la medida necesaria para restablecer la dinámica del excedente económico y, en consecuencia, la dinámica de la acumulación de capital y el consumo privilegiado de los estratos superiores.

No crean ustedes que esta expresión es tan clara y manifiesta en su profundidad social como yo acabo de explicarla. Pero es el trasfondo del monetarismo que se aplica tanto en los centros como en la periferia, sobre todo en la periferia latinoamericana. $Y$ esto tiene cierta consistencia teórica en las teorías convencionales, porque estas teorías sostienen que una de las fallas del sistema está precisamente en el poder sindical y político de la fuerza de trabajo: por Io tanto hay que dominarlo, hay que destruir ese poder hasta que se acepte un nivel de salario que permita la competividad de las empresas.

Lo que se olvida en estas teorías, y vuelvo a insistir que es un. fenómeno de omisión de la estructura social, es que la única fuerza del sistema que ha habido - históricamente, sobre todo, desde fines del siglo xix hasta hoy- para restablecer, para dar cierta aptitud a la fuerza de trabajo en sus distintas jerarquías, para participar en el fruto del progreso técnico, ha sido el poder sindical y político que se opone al poder de los estratos superiores para captar en forma de excedente económico el fruto del crecimiento de la productividad. Las teorías clásicas han sostenido siempre que el 
sistema, si se deja obrar a las fuerzas del mercado, tiende a que el fruto del progreso técnico se difunda socialmente. Pero no es así: no se difunde socialmente. Ese fruto se retiene primariamente por los estratos superiores en donde está la mayor parte de la acumulación de capital de las empresas. En consecuencia, lo que queda a la fuerza de trabajo es simplemente recurrir a su poder sindical y político, y cuando se pretende vencer a ese poder podrá lograrse tal vez, en última instancia, que la fuerza de trabajo vaya cediendo en virtud de la desocupación. Si alguna vez sobreviene la reactivación de la economía ¿se va a poder evitar de nuevo el poder sindical y político de la fuerza de trabajo, o se va a caer en un nuevo ciclo inflacionario resultante del desequilibrio entre consumo y acumulación? Esa es la gran incógnita. A mi juicio el problema no es soluble; no es soluble desde ese punto de vista.

La otra forma de política monetarista es la siguiente: de acuerdo con la ortodoxia, podría evitarse que el crecimiento del Estado, de su consumo civil y militar, se transforme en déficit fiscal si se aplica una rígida política de aumento de los impuestos en la medida en que no se pueden reducir los gastos del Estado. Pero he aquí que el impuesto también se vuelve inflacionario cuando recae en gran parte sobre las espaldas de la fuerza de trabajo y ésta, en virtud de su poder sindical y político, ha ido desarrollando el poder de resarcirse de los impuestos. De manera que ya se traduzca el aumento de los gastos del Estado en déficit claro y manifiesto, ya en impuestos que se cubren en esta forma inflacionaria, en última instancia el fenómeno viene a ser el mismo en el fondo, aunque con diferencias formales. ¿Cómo se trata entonces de combatir? ¿Qué forma, qué segundo tipo de monetarismo se aplica en este caso? Por supuesto el déficit fiscal manifiesto tiene que cubrirse generalmente en forma inflacionaria. Es lo que ha estado ocurriendo en los Estados Unidos de América, donde se han agregado otras formas de inflación social. El financiamiento del deficit a través de la expansión crediticia crea una inflación cada vez mayor, y por supuesto a la fuerza de trabajo se la compensa subiendo los sueldos y salarios.

Para evitar esa consecuencia, porque la inflación llega a preocupar a todas las clases sociales, se ha inventado una fórmula muy interesante: no cubrir el déficit ni con impuestos ni con medidas inflacionarias de expansión crediticia, sino acudiendo al ahorro público. O sea, que el exceso de consumo del Estado se cubriría con una restricción voluntaria del consumo privado por parte de quienes contribuyan con su ahorro a la compra de títulos del Estado. Esa es la razón por la cual las tasas de interés han subido en forma más extraordinaria que nunca en la historia del capitalismo. Pero, ¿por qué tiene que encarecerse simultáneamente el dinero que crean los bancos, el dinero que surge del sistema bancario? Porque para mantener esas altas tasas de interés del ahorro se suben tam- 
bién las tasas de interés del dinero bancario, restringiendo fuertemente el crédito. Entonces esta restricción del crédito se aplica por medio de altas tasas de interés. ¿Por qué razón tiene que acompañarse este proceso de un aumento de las tasas de interés bancario? Para evitar que los fondos creados por el sistema bancario se trasladen al mercado financiero para comprar títulos, en cuyo caso los títulos no se pagarían con el ahorro genuino del público sino con la expansión monetaria, o sea que los efectos inflacionarios serían los mismos. De manera que tiene su lógica el subir enormemente las tasas de interés bancario mediante una restricción crediticia.

Pero, ¿cuál es la consecuencia, cuál es el costo de ir disminuyendo la inflación en esta forma, con el ahorro del público? Primero, encarecer el ahorro para la actividad económica. Segundo, Ia restricción del crédito priva a las empresas del dinero que necesitan para acrecentar su capital de trábajo, su capital circulante. Es indispensable y absolutamente correcto expandir el crédito para dax capital de trabajo a las empresas, lo que se traduce al cabo de cierto tiempo en un incremento de la producción. Pues bien, Ia restricción crediticia y la elevación de la tasa de interés, sacrifican la actividad económica y provocan un receso de la economía y un fenómeno de desocupación, de tal manera que el costo social de esta política monetaria es igual que el de la otra política minetaria. Ya se aplique la restricción crediticia directamente o ya se la aplique para facilitar el alza de las tasas de interés y la atracción del ahorro, las consecuencias son exactamente las mismas. O sea, reducir la inflación, pero a costo de la contracción de la actividad económica y la desocupación de la economía, lo cual también lleva por ssupuesto a tratar de forzar el nivel de salarios hacia abajo, que es lo que estamos viendo en los Estados Unidos de América.

Si eso fuera un remedio, si no fuera un expediente transitorio que va a ser luego superado si alguna vez se reactiva la actividad económica, habría que pensar seriamente en aceptar un sacrificio social transitorio para lograr el relanzamiento de la economía. Pero no es así. No es así. Porque cuando la economía se reactive, volverá a presentarse el fenómeno de reajuste de sueldos y salarios, que es la forma que tiene la fuerza de trabajo de participar ya que, por el simple juego de las fuerzas económicas del mercado le sería muy difícil hacerlo, si no imposible.

Para mí ésta es la significación del monetarismo en sus dos versiones, $y$ las consecuencias no son solamente internas para el país en que se está practicando esa política, para el centro principal del capitalismo - los Estados Unidos de América- sino que sus efectos trastornadores se van extendiendo a todo el mundo. La preocupación creciente de los países europeos, para no decir nada de los países latinoamericanos y del resto de los países en desarrollo, es manifiesta: las altas tasas de interés están produciendo una contracción de la actividad económica mundial, un fenómeno agudo y cre- 
ciente de desocupación, cuyas consecuencias sociales șon evidentes $y^{\prime}$ cuyas consecuencias políticas pueden ser sumamente graves en todo el mundo. Ese es el resultado de una política, el resultado de no querer ver una realidad y de no buscar nuevas fórmulas que superen esas fórmulas tradicionales que podían aplicarse en la época en que no había poder sindical y político, o que era muy débil, pero que no se pueden aplicar en la actualidad. Hoy nos encontramos con un fenómeno real que, en el fondo, proviene de la evolución de la estructura de la sociedad.

$\mathrm{Ha}$ de comprenderse que, frente a estos acontecimientos, vuelvan a mi memoria episodios muy intensos de la gran depresión mundial del decenio de 1930, en que me correspondió participar, como joven economista al servicio del Estado de mi país, procurando encontrar la forma de atenuar, por lo menos, las consecuencias de los graves acontecimientos que se producían. Así como el epicentro de esta crisis se encuentra hoy en los Estados Unidos de América, el epicentro de la gran depresión también estuvo en los Estados Unidos.

Creíamos los economistas, guiados por lo que se decía en los centros, que era un ciclo intenso, pero que "la recuperación", ese era el lenguaje que se usaba, estaba a la vuelta de la esquina. Pero no estuvo a la vuelta de la esquina, porque la restricción bancaria provocó una verdadera histeria. La restricción del crédito fue feroz. La desocupación llegó a altísimas cifras, pero eso no fue todo. Los Estados Unidos - y eso es muy difícil explicar teóricamente- decidieron combatir la depresión subiendo intensamente los derechos de aduana frente al resto del mundo. Estos dos fenómenos, la contracción de la economía y la elevación del proteccionismo, provocaron la quiebra del sistema multilateral de pagos y comercio que tan bien había venido funcionando en el mundo. El mundo fue lanzado al bilateralismo, o sea el propósito de cada país, fuera de los Estados Unidos, de hacer frente a Ias consecuencias negativas de la depresión, a la pérdida de sus exportaciones, con medidas restrictivas de sus importaciones. Pero para no extender esas medidas, los otros países circunscribieron su aplicación a los Estados Unidos. Esa es la significación del bilateralismo. Y mal que mal esos pafses fueron saliendo a flote gracias a un bilateralismo impuesto por lo que pasaba en el epicentro de aquella crisis. Vino luego la guerra, la Segunda Guerra Mundial, y se tardó muchos años en restablecer el sistema multilateral de comercio y pagos. Las consecuencias de esa política, equivocada a mi juicio, no vacilo en decirlo, fueron muy prolongadas y muy profundas para todo el mundo.

Yo tuve, pues, que comenzar mi vida activa de economista bajo la gran depresión mundial y ahora, ya muy tarde en mi vida, estoy presenciando otra crisis del capitalismo. Entre estos dos extremos 
¿qué ha sucedido? Los países desarrollados han tenido un período. de larga bonanza, de extraordinarias tasas de crecimiento, como no se habian dado antes en la historia del capitalismo. Y, sin duda alguna, nuestros países en desarrollo pudieron aventajarse de esas tasas extraordinarias de crecimiento en los centros e iniciar exportaciones industriales, algunos de ellos con bastante éxito. Eso fue un dato positivo acompañado de consecuencias muy negativas.

En primer lugar, y me voy a referir especialmente a la América Latina, nos dejamos encandilar por la prosperidad de los centros. Esa prosperidad, ese fenómeno de encandilamiento; nos indujo a no continuar con una política que estaba dando resultados, que era la sustitución de importaciones, no en el marco estrecho de cada país, sino procurando ampliar el ámbito del comercio interregional. Fuimos al otro extremo. Anteriormente había economistas que sostenían, política equivocada, que la sustitución à outrance de las importaciones era la solución de los problemas de desarro1lo. Había que combinarla con la exportación de manufacturas. Pero el péndulo fue al otro lado en la gran prosperidad de los centros. Abandonamos la sustitución y las iniciativas de comercio recíproco entre los países de la región, se debilitaron considerablemente, porque creíamos que ya se abría una nueva era para el mundo, en la cual las exportaciones de manufacturas a los centros iban a resolver los grandes problemas de estrangulamiento exterior que habían caracterizado a esos países. Nos dejamos seducir, lo que es natural, por las consecuencias de la prosperidad de los centros. El péndulo fue al otro lado, nada de sustitución, nada de esfuerzos de comercio recíproco, todo nuestro porvenir está en el crecimiento hacia afuera, en la explotación de los mercados de los centros.

Más aún, esa gran prosperidad de los centros se extendió rápidamente, frenéticamente en muchos casos a la periferia latinoamericana. Tratamos de imitar de más en más sus formas avanzadas de consumo, debido a las grandes disparidades en la distribución del ingreso. No cabe duda alguna de que las empresas transnacionales han tenido un gran papel en esta imatación del consumo. Pero la base de ese fenómeno ha estado en la mala distribución del ingreso que caracteriza a la América Latina y a otros países en desarrollo. Eso es lo que dio a los grupos sociales superiores la posibilidad de asimilar rápidamente las formas de consumo de los centros, en detrimento de la acumulación de capital reproductivo, que es lo único que puede resolver nuestros problemas de exclusión social, o sea, el hecho de que grandes masas de la población quedan rezagadas en el fondo del sistema, con bajos ingresos, con muy baja productividad y muchas de ellas desocupadas, porque no se ha acumulado suficiente capital reproductivo que haga crecer el empleo y la productividad de las masas.

Algo elemental en materia de desarrollo económico no ha podido cumplirse debido al desperdicio del potencial de acumulacion 
de capital, en virtud de la distracción de recursos parà la implantación creciente de las formas privilegiadas de consumo en la periferia latinoamericana. A eso se agrega, por supuesto, el alto ritmo de crecimiento de la población. Durante esos años de prosperidad también noșotros, en América Latina, alcanzamos en promedio altas tasas de crecimiento; sin embargo, esa gran masa, en términos absolutos, sigue siendo la misma que antes; no se ha avanzado en la solución de este grave problema social y humano. De manera que, mirando hacia afuera, hemos abandonado lo que, a mi juicio, era una política que con todos sus defectos y fallas considerables -que las tuvo- debiera haberse seguido, aprovechando la experiencia adquirida para irla depurando. Eso desde el punto de vista exterior; internamente hemos malogrado en gran parte el potencial de acumulación de capital que se requería y que responderfa. a la exigencia dinámica del sistema.

En aquellos años de la gran depresión conmenzó en la América Latina un fenómeno de emancipación intelectual que consistía en contemplar con sentido crítico las teorías de los centros. Y ello sin una actitud de arrogancia intelectual -esas teorias tienen gran valor- sino dándose cuenta de que había que estudiarlas con sentido crítico. Debo decir, señor Secretario General, que las Naciones Unidas han desempeñado un gran papel en ese examen crítico que nos llevó a esforzarnos por buscar.nuestras propias vías del desarrollo -vías no imitativas- a tratar de comprender esta realidad y responder a las exigencias económicas, sociales y moralés del desarroIIo - vías de equidad. Fuimos avanzando con enormes obstáculos, pero cuando vinieron esos grandes años de prosperidad y nos dejamos deslumbrar por los centros, ese esfuerzo de búsqueda de nuestros propios caminos quedó interrumpido. No solamente eso, sino que hubo retorno en buena parte de la América Latina de las teorías neoclásicas bajo cuya vigencia nos habiamos desarrollado antes de la gran depresión mundial; para responder a los intereses hegemónicos de los centros y de los grupos hegemónicos de la periferia, pero dejando al margen la gran masa de la población a la cual no había llegado sino en forma incipiente la industrialización. Ese fue el modelo que tratamos de seguir, de ir corrigiendo gradualmente a la luz de la experiencia.

Pues bien, esos años de prosperidad, a pesar de todas sus ventajas, no solamente nos hicieron perder el rumbo, nos hicieron abandonar o debilitar los esfuerzos para encontrar nuestro propio camino de desarrollo periférico, sino que nos dejaron sometidos al retorno de esas ideas neoclásicas que habían sido absolutamente inadecuadas para promover el proceso de industrialización de la América Latina. En varios de nuestros países hemos presenciado los excesos del llamado liberalismo económico que solamente puede andar cuando se suprime el liberalismo político Es decir, dos formas de liberalismo que surgieron de la misma vertiente filosófi- 
ca, hace muchos años terminaron dislocándose. El implantar el liberalismo económico en algunos países llevó a la necesidad, o fue más bien la consecuencia de haberse establecido gobiernos de fuerza que doblegaban el poder sindical y político de la fuerza de trabajo y creían que con las leyes del mercado resolverían sus grandes problemas. Hemos sido intoxicados por las teorías convencionales. Yo creo que ya los países que las adoptaron con entusiasmo se están dando cuenta de sus consecuencias funestas. Pero se siguen proclamando desde el hemisferio norte, y sobre todo desde el país más avanzado del hemisferio norte, ciertas teorías convencionales que son incompatibles con la aceleración del desarrollo y con la orientación social del desarrollo.

Se espera que las fuerzas del mercado, las llamadas leyes del mercado, van a resolver nuestros problemas fundamentales de desarrollo. Y quiero hacer esta declaración: yo reconozco que las fuerzas del mercado tienen una gran importancia, pero no nos resuelven los problemas fundamentales. ¿Acaso las fuerzas del mercado nos han resuelto el problema de la explotación irresponsable de los recursos naturales, del medio ambiente, de la distribución del ingreso y de la acumulación de capital? El mercado tiene un gran valor y hay que preservarlo, porque la alternativa es la determinación de las decisiones fundamentales del sistema desde arriba - por los que están en la cúspide del sistema- lo cual no es compatible con el avance del proceso de la democratización ni con las libertades políticas e individuales. Pero de eso a creer que esas fuerzas del mercado por sí solas van a resolver todos los problemas, es un profundo error. El mercado no tiene tal magia. Es necesario combinarlàs con la intervención del Estado, sin que se haga necesario entrar en el detalle del funcionamiento de la economía, sino manejar inteligentemente los resortes del sistema. Es decir, tenemos que dejarnos guiar por la racionalidad. Se ha creído, a la luz de las teorías convencionales, que había una racionalidad en la economía. ¿Racionalidad, cuando vemos todos los males que estamos presenciando en este momento? ¿Es que es una racionalidad la que obedece en última instancia a los intereses hegemónicos internos y externos? Hay aquí una racionalidad, pero no desde el punto de vista colectivo.

Hemos estado largo tiempo esperando que el juego de las leyes del mercado, según los grandes teóricos, nos resolvieran los problemas del desarrollo y de la distribución del ingreso. Se ha creído que las fuerzas del mercado iban a traer la difusión de los frutos del progreso técnico. Sostengo que no es así. Sostengo que hay que buscar una nueva racionalidad, pero inspirada no en intereses hegemónicos: inspirada no solamente en objetivos económicos y sociales sino en objetivos eminentemente éticos. Es lo que hay que volver a introducir en la economía. Volver a la economía política y no solamente a la economía a secas para pasar, tras un duro es- 
fuerzo, por medio de la persuasión y el esclarecimiento, a la acción. Desde luego, si miráramos hoy los momentos que estamos atravesando no podríamos ser optimistas. Yo creo que hay que seguir en la lucha, que no solamente concierne al ámbito internacional sino a nuestros propios países. No se trata solamente de un nuevo orden económico internacional sino de un nuevo orden económico social y ético interno. Esos son los grandes problemas que tenemos que resolver en la América Latina tras duros sacrificios. 